\title{
Aggression as a function of genetic relatedness in the sea anemone Actinia equina (Anthozoa: Actiniaria)
}

\author{
V. L. G. Turner ${ }^{1,3, *}$, S. M. Lynch ${ }^{1,4}$, L. Paterson ${ }^{1}$, J. L. León-Cortés ${ }^{2}$, J. P. Thorpe ${ }^{1}$ \\ ${ }^{1}$ School of Biological Sciences, University of Liverpool, Port Erin Marine Laboratory, Port Erin IM9 6JA, Isle of Man, British Isles \\ ${ }^{2}$ Departamento de Ecología y Sistemática Terrestre, El Colegio de la Frontera Sur Carr. Panamericana y Periférico Sur, \\ s/n San Cristóbal de las Casas, Chiapas 29290, México \\ ${ }^{3}$ Present address: Dunstaffnage Marine Laboratory, Oban PA37 1QA, Argyll, Scotland, United Kingdom \\ ${ }^{4}$ Present address: Faculty of Community and General Education, Isle of Man College, Douglas IM2 2RB, Isle of Man, British Isles
}

\begin{abstract}
The beadlet sea anemone Actinia equina (L.) shows a well-documented sequence of aggressive responses towards conspecific individuals. Aggression is also shown towards sea anemones of certain other species. A study was carried out to assess aggressive responses of $A$. equina to other anemones over a wide range of levels of genetic divergence from genetically identical individuals (clonemates) to various other species, all of which were potentially sympatric. The other species used were the dahlia anemone Urticina felina (L.), the gem anemone Bunodactis verrucosa (Pennant), the snakelocks anemone Anemonia viridis (Forskål), the plumose anemone Metridium senile (L.) and the strawberry anemone Actinia fragacea Tugwell. Intraspecific aggression was also studied in A. fragacea. A. equina exhibited high levels of aggression to all the other species and to unrelated (i.e. non-clonal) individuals of its own species, but was never aggressive to clonemates. The levels of aggression shown by $A$. equina were found to correlate with the genetic divergence of the other anemone. It was also noted that $A$. equina only left damaging acrorhagial peels on conspecific individuals, whereas $A$. fragacea never left a peel on other $A$. fragacea, but produced peels during all successful 'fights' against $A$. equina. It is suggested that the non-self recognition system, which triggers the acrorhagial application behaviour in A. equina, is not species-specific, although the occurrence of acrorhagial peeling may be species-specific.
\end{abstract}

KEY WORDS: Self recognition · Non-self · Clones · Spatial competition · Interspecific aggression Resale or republication not permitted without written consent of the publisher

\section{INTRODUCTION}

Various sea anemone species (Anthozoa, Hexacorallia, Actiniaria) possess specialised nematocyst-bearing structures, which are considered to have evolved for use in aggressive encounters with other anthozoans (Shick 1991). In a number of mesomyarian and acontarian anemones, this function is carried out by catch tentacles; in contrast, species of the family Actiniidae mostly use a ring of structures called acrorhagi, which are normally located on the fosse of the column at the base of the tentacles (see Manuel 1988). Among the other hexacorallians, apparently analogous specialised nematocyst-bearing structures are also found in sev-

*Email: vlgt@dml.ac.uk eral hard coral species (Anthozoa, Hexacorallia, Scleractinia) in which long 'sweeper' tentacles develop on polyps around the periphery of the colony (e.g. Chornesky 1985, Peach \& Hoegh-Guldberg 1999). These tentacles bear large numbers of nematocysts and are considered to serve a function in aggressive encounters with other anthozoans (Chornesky 1985, Langmead \& Chadwick-Furman 1999a,b).

The aggressive behaviour of various anemone species has been described (e.g. Bonnin 1964, Francis 1973, Williams 1978, Bigger 1980, Ayre \& Grosberg $1995 \mathrm{a}, \mathrm{b})$ and intraspecific aggression within the genus Actinia is particularly well documented (e.g. Bonnin 1964, Brace \& Pavey 1978, Brace et al. 1979, Ayre 
1982). It appears that all acrorhagi-bearing species which have been studied to date exhibit a sequence of behaviour similar to that originally described for Actinia equina by Bonnin (1964). Initial tentacular contact is followed by the expansion and bending of the column, acrorhagial inflation, 'overtopping' of the opponent and application of the acrorhagi to the column of the adversary. Frequently, a peel of acrorhagial tissue is then left behind causing localised necrosis of the column. It has been suggested that the aggressive response is triggered by glycoprotein recognition molecules on the tentacles (Sauer et al. 1986).

The acontarian anemone Metridium senile possesses both catch tentacles and acontia (Hand 1955, Williams 1975, Purcell 1977). Catch tentacles may form from feeding tentacles and are considered to be used for offence towards non-clonemates of the same sex (Kaplan 1983) and in interspecific aggressive encounters. Acontia are threadlike extensions of the mesenteries which, when a sea anemone is disturbed, are extruded through tiny perforations in the column (cinclides) and are used for defence against predators (e.g. the nudibranch Aeolidia papillosa; see Hall et al. 1982).

Despite the extensive literature on aggression in sea anemones, there are currently few data on interspecific aggression, although in hard corals this is considered important in ecological competition for space (e.g. Sheppard 1979, Abelson \& Loya 1999). The present work investigates the acrorhagial responses of Actinia equina to other anemones over a wide range of levels of genetic divergence from clonemates to various potentially sympatric species. Specifically, it is intended to test the hypothesis that since there is likely to be a correlation between the divergence of glycoprotein genes and overall genetic divergence, the level of aggression exhibited by $A$. equina may be related to genetic divergence.

Actinia equina is known to brood asexually produced offspring (Orr et al. 1982). It is generally accepted that ramets of the same clone of anthozoans will not recognise one another as non-self given, that they are genetically identical, and therefore they are unlikely to exhibit intraclonal aggression (e.g. Francis 1973, Ayre 1982). However, this has not been investigated in A. equina. Therefore, we also aim to investigate intraclonal aggression in this species.

\section{MATERIALS AND METHODS}

To produce 'clones' of Actinia equina, 17 individuals were collected intertidally from Port Erin Bay (Isle of Man, British Isles, $54.04^{\circ} \mathrm{N}, 4.46^{\circ} \mathrm{W}$ ) and were taken back to the laboratory, where each was sectioned ver- tically into 2 equal halves. Each half was then left to heal for a few weeks; the cut edges of each half naturally push together and rejoin to form a smaller anemone, and note that sewing them up does not work because the stitches simply drop out. Two 'halves' died, but the others repaired themselves to produce apparently normal, if smaller, anemones. This resulted in 15 surviving clonal pairs of $A$. equina available for experimental purposes. A. equina is known to brood cloned offspring (Orr et al. 1982); however, to grow these in the laboratory to adult size would take too long and adults of the same clone cannot be readily identified on the shore.

To study aggression between different Actinia equina individuals and between various anemone species, samples of 10 specimens of each of the 6 anemone species were collected. Urticina felina (L.), Bunodactis verrucosa (Pennant), Anemonia viridis (Forskål) and a red-columned and green-footed morph of Actinia equina (a low shore morph; see Perrin et al. 2000) were collected intertidally from various shores around the Isle of Man. A low-shore morph of $A$. equina was chosen as these individuals were the most likely to be in contact with subtidal species such as Metridium senile and $U$. felina. All specimens were taken from pools separated by at least 3 metres (to minimise the possibility of collecting from the same clone in the clonally reproducing $A$. equina and $A$. viridis). Specimens of $M$. senile (L.) were collected subtidally using SCUBA equipment around the Isle of Man. Individuals were taken from depths of 2 to $3 \mathrm{~m}$ and were at least $5 \mathrm{~m}$ apart. Specimens of Actinia fragacea Tugwell were collected from an intertidal boulder field at Trevaunance Cove, St. Agnes, Cornwall (SW England; $50.13^{\circ} \mathrm{N}$, $\left.5.13^{\circ} \mathrm{W}\right)$. Since size is known to affect the outcome of intraspecific contests in A. equina (see Brace \& Pavey 1978), only anemones of ca. $20 \mathrm{~mm}$ pedal disc diameter were collected for this species. Sea anemones which were inadvertently damaged were not collected.

After collection, all anemones were placed in separate compartments of seawater-filled partitioned boxes for transportation to the marine laboratory at Port Erin. At the laboratory, anemones were maintained in an indoor non-tidal 791 aquarium with aerated (air stone) through-flowing seawater at ambient temperature. Individuals were allowed to attach to either acetate strips or pieces of scallop Pecten maximus shells that had been previously submerged in seawater for at least $2 \mathrm{~d}$ to allow the growth of a surface biolayer to facilitate anemone attachment. Anemones were placed in individual numbered submerged plastic containers $(500 \mathrm{ml})$ with nylon netting fastened across the top to keep them in but allow water circulation. Anemones were fed with fresh scallop (Pectinidae spp.) and/or live Artemia every $10 \mathrm{~d}$ and were allowed 
6 wk to acclimate before any behavioural studies were undertaken.

All behavioural encounters were staged within a separate 6.31 tank containing aerated sea water at $8 \pm$ $2{ }^{\circ} \mathrm{C}$. For each encounter, the contestants were selected using random number tables (Zar 1984). No 2 anemones fought each other more than once. Before each fight, the 2 anemones concerned were placed into the tank and allowed to acclimate for $10 \mathrm{~min}$. Only individuals with fully expanded oral discs were used. The 2 anemones were then moved closer together, so that tentacular contact was established. This initial contact was restricted to 2 or 3 ten-tacles. Encounters were observed for $1 \mathrm{~h}$ and a contest was deemed to have finished when 1 or both individuals either closed, displayed no further aggression or moved away. The occurrence of each of 4 stages of behaviour was recorded: (1) the initial tentacular response; (2) acrorhagial inflation; (3) acrorhagial application onto the column of the adversary; and (4) acrorhagial peeling (deposited on the column of either anemone).

A contestant was considered to have exhibited an acrorhagial response if at least Stage 3 was reached. The period (min) from first tentacular contact until the inflation of the acrorhagi (the excitation period) was also recorded. No encounters were set up within a $48 \mathrm{~h}$ period following feeding and, for any given anemone, conflicts were at not less than $24 \mathrm{~h}$ intervals. If individuals were damaged during fights, they were allowed to heal before being used again.

Intraspecific encounters were staged for Actinia equina and Actinia fragacea, and interspecific encounters were set up between $A$. equina and all 5 other species. Of the species incorporated into our study, Actinia equina, A. fragacea, Anemonia viridis and Metridium senile are usually considered to be potentially combative. However, although A. viridis is considered to be potentially aggressive (Sauer et al. 1986), preliminary experiments showed that the individuals used in our study did not aggress towards others of the same species. Further examination confirmed the absence of acrorhagi (see also Stephenson 1935). Acrorhagi are also absent in Urticina felina and Bunodactis verrucosa (Manuel 1988) and thus, these species are generally considered non-aggressive.

For the analysis of both intraspecific and interspecific fight/no fight data, chi-square analyses with 1 degree of freedom were used with Cochran's continuity correction as described by Zar (1984). A binomial test was used to test for differences in the intraclonal aggression data. The excitation periods of Actinia equina were log-transformed to generate a normal distribution wherever the variances greatly exceeded the mean. A $t$-test and a 1-way ANOVA (with a post hoc Tukey's test) were used for the comparison of the lengths of the intraspecific and interspecific excitation periods respectively. Forward logistic regression procedures were performed with the logit (L) of the probability of interspecific reaction (p) on anemones as the dependent variable, where $\mathrm{L}=\ln [\mathrm{p} /(1-\mathrm{p})]$, and with the type of interaction ( $A$. equina facing a given species) as an independent variable. For the purpose of this analysis, the acrorhagial inflation data were scored with reactions being assigned the value 1 and no-reactions 0 , and the independent variables (permutation type) were classified as intervals rather than categories. The score statistic and the change in likelihood ( -2 ln LR) were used, respectively, for entering and removing variables from the model (for details see Trexler \& Travis 1993, Norusis 1994). Fisher's exact probability was used to assess the difference in the proportion of peels exhibited in intraspecific and interspecific acrorhagial responses by Actinia fragacea.

Estimates of genetic divergence between the various anemone species were based on figures for Nei's (1978) genetic identity, I, and were taken from an earlier study by Solé-Cava et al. (1994). A Spearman's rank order correlation was used to correlate aggression with genetic identity.

\section{RESULTS}

\section{Intraclonal aggression}

All 15 clonal pairs of Actinia equina were brought into contact with each other, but none showed any aggression towards its 'other half'. Using the same individuals, 30 encounters were also staged between individuals from different clones. Of these, 24 (80\%) resulted in an acrorhagial attack by at least 1 of the contestants. This difference is highly significant (2-tailed binomial test: $\mathrm{p} \ll 0.0001)$.

\section{Intraspecific aggression}

Actinia equina showed greater levels of intraspecific aggression (76\%) than did Actinia fragacea $(16 \%)$ (Table 1). The difference between the 2 species in the proportion of intraspecific encounters resulting in aggression (i.e. an acrorhagial application by at least 1 of the contestants) was highly significant (chi-square test: $\chi^{2}=24.14$, df $=1, \mathrm{p} \ll$ 0.001 ). The locomotory withdrawal of 'losers' varied between 2 and $3 \mathrm{~cm}$ and took 2 to $5 \mathrm{~min}$. The difference in the log-transformed excitation periods between $A$. equina versus $A$. equina and $A$. fragacea versus $A$. fragacea (Table 1) was not significant ( $t$-test: $t=-0.735, \mathrm{p}>0.05)$. 
Table 1. Frequencies of various criteria of intraspecific agonistic behaviour exhibited by Actinia equina and A. fragacea. $\mathrm{n}=$ number of encounters, Tent. = number of encounters in which a tentacular response occurred, Inf. = number of encounters where acrorhagial inflation occurred, App. = numbers of encounters in which acrorhagial application occurred, Peel = number of encounters in which an acrorhagial peel was left by the aggressor, Ret. = the number of encounters in which the intraspecific opponent initiated aggression or retaliated, $\mathrm{EP}=$ the mean and SD of the excitation period (time in minutes taken for the anemone to inflate the acrorhagi) and $\mathrm{L}=$ locomotory withdrawal of loser

\begin{tabular}{|lrrrrrrrr|}
\hline Species & $\mathrm{n}$ & Tent. & Inf. & App. & Peel & Ret. & EP (min) & L \\
\hline A. equina & 45 & 43 & 34 & 34 & 29 & 6 & $12.6 \pm 13.0$ & 25 \\
A. fragacea & 45 & 13 & 8 & 7 & 0 & 1 & $13.0 \pm 9.37$ & 3 \\
\hline
\end{tabular}

tentacles) for which interspecific contests with Actinia equina were staged (A. fragacea and Metridium senile), both exhibited some level of aggression towards A. equina (Table 4). $M$. senile extruded acontia towards A. equina on 16 occasions, each attack causing severe necrosis ( 1 individual of A. equina took $2 \mathrm{wk}$ to recover fully). The recovery period from acontarian attacks was generally longer than that from peels left by $A$. fragacea. The effects of acrorhagial application by A. equina on anemones of other species (without the application of a peel) was

\section{Interspecific aggression}

Actinia equina showed an acrorhagial response to at least some individuals of all the other species used (Table 2). Over these species, the proportion of interspecific encounters resulting in aggression by A. equina did not differ significantly (chi-square test: $\chi^{2}=1.11$, df $=4, \mathrm{p}>0.05$ ). However, a forward logistic regression analysis run on all interspecific excitation periods showed that the probability of an acrorhagial reaction was enhanced when $A$. equina faced $A$. fragacea and decreased when $A$. equina faced Anemonia viridis, Urticina felina, Bunodactis verrucosa and Metridium senile (in decreasing order) (Table 3). The levels of acrorhagial response exhibited by $A$. equina to the other 5 species included in our study (Table 2) correlates significantly with genetic identities (Nei 1978; see Table 2) estimated between $A$. equina and these other species by SoléCava et al. (1994) (Spearman rank correlation: $\mathrm{R}_{\mathrm{S}}=$ 0.917, $\mathrm{n}=5, \mathrm{p}<0.05)$.

All log-transformed intraspecific excitation periods for Actinia equina and all interspecific excitation periods (Tables 1 $\& 2$ respectively) were compared within the same data set. Although a significant difference was found (1-way ANOVA: $F_{5}=3.402, \mathrm{p}=0.007$ ), post hoc pairwise comparisons of all mean excitation periods revealed that no significant differences were found between all but 1 interspecific permutation type (Actinia equina vs Bunodactis verrucosa and $A$. equina vs Anemonia viridis, Tukey's test: $Q=4.908, \mathrm{p}<0.05)$. This corresponded to the longest and shortest mean interspecific excitation period respectively (Table 2 ).

Of the 2 potentially combative species (i.e. those with acrorhagi or catch apparent only in Anemonia viridis and Bunodactis verrucosa (Table 5). Localised necrosis of tentacular tissue occurred, resulting in a mechanical impediment to the tentacles. Both $A$. viridis and $B$. verrucosa usually took about $3 \mathrm{~d}$ to recover. The locomotory withdrawal of losing anemones varied from 2 to $5 \mathrm{~cm}$, took 2 to $10 \mathrm{~min}$ and was exhibited by $A$. equina, $A$. fragacea and A. viridis. Occasional complete detachment from the substratum occurred in $A$. equina and $A$. viridis following severe repeated attacks by the winner. This detachment was achieved by the inflation of the pedal disc and often the inversion of the anemone.

\section{Acrorhagial peeling}

Consistently, throughout our study, Actinia equina deposited an acrorhagial peel only onto other $A$. equina (Table 1) and never onto anemones of other species (Table 2). Analysis of the proportions of acrorhagial applications leading to peeling showed a highly signif-

Table 2. Frequencies of various criteria of interspecific aggressive behaviour exhibited by Actinia equina to other sea anemone species. Results refer to the responses of $A$. equina towards the different species listed in the first column. Nei's I = the genetic identity found between this genetic morph of A. equina and each other combatant species (from Solé-Cava et al. 1994). All other abbreviations as in Table 1

\begin{tabular}{|lccccccccc|}
\hline A. equina vs & $\mathrm{n}$ & Tent. & Inf. & App. & Peel & Nei's I & Ret. & EP (min) & L \\
\hline $\begin{array}{c}\text { Actinia } \\
\text { fragacea }\end{array}$ & 25 & 24 & 22 & 18 & 0 & 0.60 & 1 & $6.9 \pm 4.54$ & 3 \\
$\begin{array}{c}\text { Anemonia } \\
\text { viridis }\end{array}$ & 25 & 25 & 15 & 15 & 0 & 0.16 & 0 & $5.7 \pm 5.30$ & 0 \\
$\begin{array}{c}\text { Urticina } \\
\text { felina }\end{array}$ & 25 & 25 & 12 & 12 & 0 & 0.23 & 0 & $13.8 \pm 8.94$ & 0 \\
$\begin{array}{c}\text { Bunodactis } \\
\text { verrucosa } \\
\text { Metridium } \\
\text { senile }\end{array}$ & 25 & 25 & 9 & 9 & 0 & 0.14 & 0 & $17.3 \pm 7.25$ & 0 \\
\hline
\end{tabular}


Table 3. Forward logistic regression analysis of interspecific excitation periods for Actinia equina measured during aggressive encounters with other anemone species. Interaction = permutation types, $\mathrm{B}=$ coefficient $(\mathrm{a}$ negative value indicates the likelihood of aggression occurring decreases with permutations 2 to 5), $\mathrm{SE}=$ standard error, Wald $=$ Wald statistic which has the chi-square distribution $\left(\chi_{1}^{2}=9.6, p=0.002\right)$, and is the square of the ratio of the coefficient to its SE, $\mathrm{N}_{1}, \mathrm{~N}_{2}=$ number of acrorhagial reactions and of no reactions, respectively

\begin{tabular}{|lrrrrrrr|}
\hline & $\mathrm{B}$ & $\mathrm{SE}$ & Wald & $\mathrm{df}$ & $\mathrm{p}$ & $\mathrm{N}_{1}$ & $\mathrm{~N}_{2}$ \\
\hline Interaction & -0.410 & 0.137 & 8.961 & 1 & 0.003 & 71 & 54 \\
Constant & 1.525 & 0.465 & 10.757 & 1 & 0.001 & & \\
\hline
\end{tabular}

Table 4. Frequencies of aggressive behaviour criteria of the 2 potentially aggressive anemone species towards Actinia equina. Results refer to the responses of the first species listed in contest permutations. Inf./Acont. $=$ the numbers of times either acrorhagi were inflated or acontia extruded; Appl. = successful application of respective fighting structures to the column of A. equina, Peel/ Nec. $=$ production of a peel or occurrence of necrosis on the column of A. equina. Other abbreviations as in Table 1

\begin{tabular}{|lcccccc|}
\hline Permutation & $\mathrm{N}$ & Inf./Acont. & Appl & Peel/Nec. & Ret & L \\
\hline $\begin{array}{l}\text { Actinia fragacea } \\
\text { vs A. equina }\end{array}$ & 25 & 5 & 5 & 5 & 3 & 1 \\
$\begin{array}{c}\text { Metridium senile } \\
\text { vs A. equina }\end{array}$ & 25 & 16 & 16 & 16 & 6 & 0 \\
\hline
\end{tabular}

icant difference between intraspecific and interspecific contests $\left(\chi^{2}=70.65, \mathrm{df}=1, \mathrm{p} \ll 0.001\right)$. Interestingly, different behaviour was observed in A. fragacea. In this species, none of the 7 intraspecific acrorhagial applications resulted in the production of a peel, whereas all 5 interspecific applications resulted in the production of a peel on the column of $A$. equina (Table 4). Although the sample size is small, the difference in the proportion of peels exhibited in intraspecific and interspecific acrorhagial responses by A. fragacea was highly significant (Fisher's exact probability: $\mathrm{p}=1.26 \times 10^{-3}$ )

\section{DISCUSSION}

In encounters between genetically identical individuals (clones) of Actinia equina, there was no inflation of the acrorhagi or any other indication of aggression. The results for intraclonal aggression in $A$. equina were very similar to those obtained by Ayre (1982, 1983) for the Australian species A. tenebrosa. He used asexually reproduced brooded offspring to test aggression within clones.

Actinia equina showed high levels of aggression towards conspecific individuals that were not from the same clone. In a previous study of aggression between various morphs of $A$. equina (Brace \& Reynolds 1989), the colour phenotype we used was found to be relatively unaggressive. The observed attack frequency in that study was only $5 \%$ in auto-phenotypic contests, which corresponds to the intraspecific contests of the present study. Our data suggest that an attack frequency of $57 \%$ would have been observed within contests of $45 \mathrm{~min}$, the time limit for contests used by Brace \& Reynolds (1989). The difference between these 2 attack frequencies is highly significant $\left(\chi^{2}=18.70\right.$, $\mathrm{df}=1, \mathrm{p}<0.001)$. It is clear that some populations of this morph of $A$. equina show variation in levels of aggression and can be more aggressive than previously thought. Although $A$. fragacea was less aggressive than $A$. equina, there was no significant difference in the excitation periods. The 2 species are closely related, and therefore it is unsurprising that they exhibit similar response times.

Not all individuals of Actinia equina elicited an acrorhagial response during intraspecific encounters. There are 2 possible explanations for our result. One is that some of the anemones collected were clones. Solé-Cava \& Thorpe (1992) researched this possibility of sampling bias in specimens of $A$. equina. The individuals they used were separated on the shore by at least $2 \mathrm{~m}$ as opposed to $3 \mathrm{~m}$, as in our study. Their results showed that out of 25 individuals, no 2 were genetically identical. This suggests that the non-aggression found in our results was probably not due to the occurrence of clones in the samples. The second explanation, as proposed by Bigger (1980), following Francis's (1973) work on the anemone Anthopleura elegantissima, suggests the possibility that individuals may not recognise all conspecifics as non-self, even when not from the same clone. The acrorhagial response of sea anemone species is considered to be an example of self and nonself recognition; Bigger (1980) suggested that, in the field, individuals are more likely to be related by sharing alleles at some loci. These alleles might include those determining the surface molecules that aid the recognition events in the acrorhagial response. Broadly similar polymorphic loci controlling histocompatibility (allorecognition) systems (reviews by Grosberg et al. 1988, Grosberg \& Quinn 1989) are thought to play a role in aggression and hence, competition for space between, for example, colonies of corals (e.g. Hidaka et al. 1985), ascidians (e.g. Cohen et al. 1998, 
Table 5. Response criteria of the non-aggressive species towards Actinia equina. Nec. = occurrence of necrosis on the column of $A$. equina. Other abbreviations as in Table 1

\begin{tabular}{|lcccc|}
\hline Permutation & N & Nec. & Ret & L \\
\hline $\begin{array}{l}\text { Urticina felina } \\
\text { vs A. equina }\end{array}$ & 25 & 0 & 0 & 0 \\
$\begin{array}{l}\text { Anemonia viridis } \\
\text { vs A. equina }\end{array}$ & 25 & 15 & 0 & 10 \\
$\begin{array}{l}\text { Bunodactis verrucosa } \\
\text { vs A. equina }\end{array}$ & 25 & 9 & 0 & 0 \\
\hline
\end{tabular}

Rinkevitch et al. 1998) and hydroids (e.g. Buss et al. 1984, Grosberg et al. 1986)

The present data indicate that the non-self recognition system which 'triggers' the acrorhagial application behaviour in Actinia equina is not speciesspecific. Even contests between $A$. equina and Metridium senile, which belong to different families, resulted in high frequencies of acrorhagial application $(32 \%)$. Mean interspecific and intraspecific excitation periods were also similar. However, both the increased tendency of $A$. equina to aggress towards the closely related Actinia fragacea (logistic regression result), and the correlation between levels of aggression and genetic difference between interspecific contestants suggests that the likelihood of nonself recognition may be associated with evolutionary divergence. This may result from the divergence of the glycoprotein recognition molecules, which are thought to be involved in non-self recognition (Sauer et al. 1986).

The inflation of the pedal disc following severe attacks probably serves as an escape response. In the field, detached sea anemones would be removed by turbulent water movement. Although the chances of successful resettlement are probably low, it can be argued that the benefits from such evasive action might well outweigh the costs of remaining and fighting the aggressor. Moving away might also risk further contact (and perhaps conflict) with other anemones. This also might explain why anemones generally moved such short distances, often just out of tentacular contact with the aggressor.

The phenomenon of acrorhagial peeling by Actinia equina appears to be species-specific, since it apparently occurs only in intraspecific encounters. Interspecific aggression in A. equina differs from that observed in Anthopleura krebsi by Bigger (1980), who reported that this anemone species even left peels on the polyps of medusae of the scyphozoan Cassiopea xamachana.

Our findings suggest the possibility of a 2-tier recognition system in Actinia equina. Tentacular contact with a non-clonemate appears often to initiate the acrorhagial response, which then progresses to acrorhagial application and occasional retaliation by the adversary. Acrorhagial peeling, however, only occurs if the application is to a conspecific individual. This may indicate a second recognition system, associated with the acrorhagus itself, in which the recognition of species-specific surface markers stimulates the peeling event.

Although not anticipated, the disparity between the exclusively intraspecific acrorhagial peeling in Actinia equina and the exclusively interspecific acrorhagial peeling in A. fragacea is also of note. Aggression in $A$. equina has been considered to be important for adult survival, since it is assumed to have a role in competition for space (Brace \& Quicke 1986). On British shores, dense populations of $A$. equina are common, and therefore intraspecific aggression may be relatively frequent. Our observations suggest that on shores in the southwest of Britain, where A. fragacea occurs, it is much less common than $A$. equina and individuals do not generally group together. Although this species is rarely found in close proximity to other individuals of $A$. fragacea, successful aggression against $A$. equina would be likely to be of ecological advantage to $A$. fragacea, since this is the species with which it would commonly compete for space. Consequently, intraspecific aggression in $A$. fragacea is likely to be less important, since the species will comparatively rarely encounter conspecific individuals. Unlike A. equina, A. fragacea does not brood offspring in the enteron (body cavity) (see Carter \& Thorpe 1981). The exhibition of the acrorhagial response by this species thus supports the suggestion of Brace \& Quicke (1986) that aggression in the genus may not be primarily concerned with establishing settlement space for cloned offspring released after internal brooding, but that it is more likely to be important in promoting the survival of the aggressing individual.

Also of interest is the apparently exceptional healing ability of Actinia equina. The capability of the species to heal itself when cut in half and to form 2 smaller anemones is probably far from unique among sea anemone species. Many Anthozoa reproduce asexually by longitudinal fission or by pedal laceration (a process by which small pieces of the foot rim slough off) and subsequently reform into small anemones (see e.g. Manuel 1988, Shick 1991), although A. equina does not use these methods. In the past, we have frequently taken tissue samples from $A$. equina for genetic analysis by cutting out a slice from the anemone (like slicing a cake). Individuals so treated almost invariably survive and heal in several days. Attempts to $\operatorname{tag} A$. equina with loops of thread or nylon inserted through the mouth and out through the body 
wall always fail because the cells of the anemone apparently 'flow' around the loop, which is rejected and falls to the bottom of the tank. Thus, it may be that in A. equina, or in sea anemones generally, cells are relatively undifferentiated and are able to undergo some sort of plastic flow, and hence, heal wounds very rapidly.

Acknowledgements. We thank C. D. Thomas for comments on the statistical analysis of the data. S.M.L. gratefully acknowledges the support of a research studentship from the Natural Environment Research Council.

\section{LITERATURE CITED}

Abelson A, Loya Y (1999) Interspecific aggression among stoney corals in Eilat, Red Sea: a hierarchy of aggression ability and related parameters. Bull Mar Sci 65:851-860

Ayre DJ (1982) Inter-genotype aggression in the solitary sea anemone Actinia tenebrosa. Mar Biol 68:199-205

Ayre DJ (1983) The effects of asexual reproduction and intergenotype aggression on the genotypic structure of populations of the sea anemone Actinia tenebrosa. Oecologia 57: 158-165

Ayre DJ, Grosberg RK (1995a) Effects of social organisation on inter-clonal dominance relationships in the sea anemone Anthopleura elegantissima. Anim Behav 51: $1233-1245$

Ayre DJ, Grosberg RK (1995b) Aggression, habituation, and clonal co-existence in the sea anemone Anthopleura elegantissima. Am Nat 146:427-453

Bigger CH (1980) Interspecific and intraspecific acrorhagial aggressive behaviour among sea anemones: a recognition of self and non-self. Biol Bull 159:117-134

Bonnin JP (1964) Recherches sur la 'réaction d'agression', et sur la fonctionnement des acrorhages d'Actinia equina L. Bull Biol Fr Belg 98:225-250

Brace RC, Pavey J (1978) Size-dependent dominance hierarchy in the anemone Actinia equina. Nature 273:752-753

Brace RC, Quicke DLJ (1986) Seasonal changes in dispersion within an aggregation of the anemone Actinia equina, with a reappraisal of the role of intraspecific aggression. J Mar Biol Assoc UK 66:49-70

Brace RC, Reynolds HA (1989) Relative intraspecific aggressiveness of pedal disc phenotypes of the beadlet anemone, Actinia equina. J Mar Biol Assoc UK 69:273-278

Brace RC, Pavey J, Quicke DLJ (1979) Intraspecific aggression in the colour morphs of the anemone Actinia equina: the 'convention' governing dominance ranking. Anim Behav 27:553-561

Buss L, McFadden C, Keene D (1984) Biology of hydractiniid hydroids. 2. Histocompatibility effector system/competitive mechanism mediated by nematocyst discharge. Biol Bull 167:139-158

Carter MA, Thorpe JP (1981) Reproductive, genetic and ecological evidence that Actinia equina var. mesembryanthemum and var. fragacea are not conspecific. J Mar Biol Assoc UK 61:79-93

Chornesky EA (1985) The consequences of direct competition between scleractinian corals: development and use of sweeper tentacles. PhD thesis, University of Texas, Austin

Cohen CS, Saito Y, Weissman IL (1998) Evolution of allore- cognition in botryllid ascidians inferred from a molecular phylogeny. Evolution 52:746-756

Francis L (1973) Intraspecific aggression and its effect on the distribution of Anthopleura elegantissima. Biol Bull 144: $73-92$

Grosberg RK, Quinn JF (1989) The evolution of selective aggression conditioned by allorecognition specificity. Evolution 43:504-515

Grosberg RK, Levitan D, Cameron B (1986) Evolution of allorecognition in the colonial hydroid Hydractinia symbiolongicarpus. Evolution 40:2221-2240

Grosberg RK, Hedgecock D, Nelson K (1988) Invertebrate historecognition. Plenum Press, New York

Hall SJ, Todd CD, Gordon AD (1982) The influence of ingestive conditioning on prey species selection in Aeolidia papillosa (Mollusca: Nudibranchia). J Anim Ecol 51:907-921

Hand C (1955) The sea anemones of central California. Part II. The endomyarian and mesomyarian anemones. Wasmann J Biol 13:37-99

Hidaka M (1985) Nematocyst discharge, histocompatibility and the formation of sweeper tentacles in the oral Galaxea fisicularis. Biol Bull 168:350-358

Kaplan SW (1983) Intrasexual aggression in Metridium senile. Biol Bull 165:416-418

Langmead O, Chadwick-Furman NE (1999a) Marginal tentacles of the corallimorpharian Rhodactis rhodostoma. 1. Role in competition for space. Mar Biol 134:479-489

Langmead O, Chadwick-Furman NE (1999b) Marginal tentacles of the corallimorpharian Rhodactis rhodostoma. 2. Induced development and long term effects on coral competitors. Mar Biol 134:491-500

Manuel RL (1988) British anthozoa. Synopsis of the British fauna No. 18 (revised). EJ Brill, Leiden

Nei M (1978) Estimation of average heterozygosity and genetic distance from a small number of individuals. Genetics 89:583-590

Norusis MJ (1994) SPSS advanced statistics 6.1. Chicago

Orr J, Thorpe JP, Carter MA (1982) Biochemical genetic confirmation of the asexual reproduction of brooded offspring in the sea anemone Actinia equina. Mar Ecol Prog Ser 7: $227-229$

Peach MB, Hoegh-Guldberg O (1999) Sweeper polyps of the coral Goniopora tenuidens (Scleractinia: Poritidae). Invertebr Biol 118:1-7

Perrin MC, Thorpe JP, Solé-Cava AM (2000) Population structuring, gene dispersal and reproduction in the Actinia equina species group. Oceanogr Mar Biol Annu Rev 37: $129-152$

Purcell JE (1977) Aggressive function and induced development of catch tentacles in the sea anemone Metridium senile (Coelenterata:Actinaria). Biol Bull 162:355-368

Rinkevitch B, Tartakova S, Gershon H (1998) Contribution of morula cells to allogenic responses in the colonial urochordate Botryllus schlosseri. Mar Biol 131:227-236

Sauer KP, Muller M, Weber M (1986) Alloimmune memory for glycoprotein recognition molecules in sea anemones competing for space. Mar Biol 92:73-79

Sheppard CRC (1979) Interspecific aggression between reef corals with reference to their distribution. Mar Ecol Prog Ser 1:237-247

Shick JM (1991) A functional biology of sea anemones. Chapman \& Hall, London

Solé-Cava A, Thorpe JP (1992) Genetic divergence between colour morphs in populations of the common intertidal sea anemone Actinia equina and Actinia prasina (Anthozoa: Actinaria) in the Isle of Man. Mar Biol 112:243-252

Solé-Cava AM, Russo CAM, Araujo ME, Thorpe JP (1994) 
Cladistic and phenetic analysis of allozyme data for nine species of sea anemones of the family Actiniidae (Cnidaria: Anthozoa). Biol J Linn Soc 52:225-239

Stephenson TA (1935) The British sea anemones, Vol 2. Ray Society, London

Trexler JC, Travis J (1993) Nontraditional regression analyses. Ecology 74:1629-1637

Editorial responsibility: Otto Kinne (Editor),

Oldendorf/Luhe, Germany
Williams RB (1975) Catch tentacles in sea anemones: occurrence in Haliplanella luciae (Verrill) and a review of current knowledge. J Nat Hist 9:241-248

Williams RB (1978) Some recent observations on the acrorhagi of sea anemones. J Mar Biol Assoc UK 58: $787-788$

Zar JH (1984) Biostatistical analysis. Prentice-Hall, New York

Submitted: March 12, 2002; Accepted: September 3, 2002

Proofs received from author(s): January 6, 2003 